\title{
Cardiac function and hypertension in patients with obstructive sleep apnea
}

\author{
This article was published in the following Dove Press journal: \\ Research Reports in Clinical Cardiology \\ 28 August 2014 \\ Number of times this article has been viewed
}

\section{Adriana Bertolami \\ Carolina Gonzaga \\ Celso Amodeo \\ Sleep Laboratory of Dante Pazzanese Institute of Cardiology, Sao Paulo, Brazil}

Correspondence: Carolina Gonzaga Sleep Laboratory, Hypertension and Nephrology Department, Dante Pazzanese Institute of Cardiology, Av Dr Dante Pazzanese, 500 Sao Paulo, SP Brazil 04012-909

Tel +55 II 50856 I 44

$\mathrm{Fax}+55$ II 50856206

Email carolinadcg@hotmail.com

\begin{abstract}
Cardiovascular disease is one of the major causes of death worldwide. Among its risk factors, obstructive sleep apnea (OSA) is a common but still underestimated condition. OSA often coexists and interacts with obesity, sharing multiple pathophysiological mechanisms and subsequent cardiovascular risk factors, such as type 2 diabetes, dyslipidemia, systemic inflammation, and in particular hypertension. There is also evidence suggesting an increased risk of arrhythmia, heart failure, renal failure, acute myocardial infarction, stroke, and death. OSA is characterized by recurrent episodes of partial (hypopnea) or complete interruption (apnea) of breathing during sleep due to airway collapse in the pharyngeal region. The main mechanisms linking OSA to impaired cardiovascular function are secondary to hypoxemia and reoxygenation, arousals, and negative intrathoracic pressure. Consequently, the sympathetic nervous and the renin-angiotensin-aldosterone systems may be overestimulated, and blood pressure increased. Resistance to treatment for hypertension represents a growing issue, and given that OSA has been recognized as the major secondary cause of resistant hypertension, clinical investigation for apnea is mandatory in this population. Standard diagnosis includes polysomnography, and treatment for OSA should include control of risk factors for cardiovascular disease, including obesity. So far, continuous positive airway pressure is the treatment of choice for OSA, impacting positively on blood pressure goals; however, the impact on long-term follow-up and on cardiovascular disease should be better assessed.
\end{abstract}

Keywords: obstructive sleep apnea, hypertension, cardiac function

\section{Introduction}

Cardiovascular disease is a major cause of morbidity and mortality worldwide. ${ }^{1}$ The diagnosis and treatment of cardiovascular risk factors, such as hypertension, dyslipidemia, and type 2 diabetes, are therefore essential to reduce cardiovascular events. ${ }^{2}$ Among the risk factors for cardiovascular disease, obstructive sleep apnea (OSA) is a common but still underestimated condition, with over $85 \%$ of patients with clinically significant and treatable OSA having never been diagnosed..$^{3-5}$

OSA often coexists and interacts with obesity, sharing multiple pathophysiological mechanisms and subsequent cardiovascular risk factors, ${ }^{6}$ such as type 2 diabetes, dyslipidemia, systemic inflammation, ${ }^{6-9}$ and in particular hypertension. ${ }^{10-13}$ There is also evidence suggesting an increased risk of arrhythmia, heart failure, renal failure, acute myocardial infarction, stroke, and death. ${ }^{7,14}$

OSA affects around $5 \%$ of the general population, and the prevalence in patients referred to sleep laboratories is 50\% using an apnea-hypopnea index (AHI) of $\geq 10$ or 15 events per hour. ${ }^{15,16}$ Among hypertensive individuals, this prevalence 
ranges from $30 \%$ to $40 \%$, while $50 \%$ of patients with OSA are hypertensive. ${ }^{7,17-19}$ When resistant hypertension is considered, the prevalence of OSA increases up to $64 \%-83 \%$, depending on the AHI considered for the diagnosis. ${ }^{20-23}$

Diurnal hypersomnia due to frequent nocturnal arousals, asthenia, snoring, and witnessed apnea are the main symptoms of OSA. When OSA is suspected, the Epworth Sleepiness Scale or the Berlin Questionnaire could be used respectively to measure daytime sleepiness and to identify patients at higher risk for OSA. ${ }^{24,25}$

Polysomnography is the standard method used to diagnose OSA and can be performed in a sleep laboratory or in the patient's home. A complete polysomnography includes records of sleep, airflow (nasal pressure), respiratory effort (thoracic and abdominal respiratory movements), electroencephalography, and oxyhemoglobin saturation.

The aim of treatment for OSA is to achieve symptom control and to reduce cardiovascular risk, so a multidisciplinary approach is indicated. The treatment of choice is continuous positive airway pressure (CPAP), but other options include oral appliances ${ }^{26-29}$ and surgery, which, after decades, is still controversial, mainly because the criteria for surgical success are not well defined. ${ }^{30}$ Nowadays, its indication is restricted to selected cases, eg, for patients with refractory OSA or for those nontolerant to CPAP use.

Since CPAP adherence is a challenging issue, using a multidisciplinary approach is recommended, including physicians, nurses, physiotherapists, etc, to support the patient, in every step of CPAP use. It should include an explanation about the definition of OSA, the associated risk factors, prognosis, and benefit from treatment. The CPAP mask should be carefully chosen, and some patients may benefit from pressure relieve configuration, and humidifier device added to CPAP machine. Patients should be encouraged to mention complaints as soon as possible in order to resolve any issues that could impair adherence with CPAP.

\section{Normal sleep and the cardiovascular system}

Some physiological changes that occur during normal sleep have been described. Nonrapid eye movement sleep accounts for about $80 \%$ of total sleep and is considered a cardiovascular relaxation state (Figure 1). ${ }^{31}$ During this period, heart rate, blood pressure, and sympathetic nervous system activity fall while vagal activity increases. There is also muscle relaxation, but basal tone is always maintained. ${ }^{31}$

Rapid eye movement (REM) sleep comprises only $20 \%-25 \%$ of total sleep and is characterized by rapid eye movement (Figure 1). It is known for its paradoxical aspects, such as the presence of hypotonia and muscle atonia associated with phasic movements and multifocal myoclonus. The electrocardiogram and breathing show an irregular pattern, with alternating episodes of hypopnea and tachypnea, and central apneas. Sympathetic discharges and intermittent increases in heart rate and blood pressure occur in REM sleep; however, these events do not increase heart rate or mean arterial pressure above the usual values of wakefulness. REM sleep is also characterized by dreams and difficulty in awakening. ${ }^{31}$

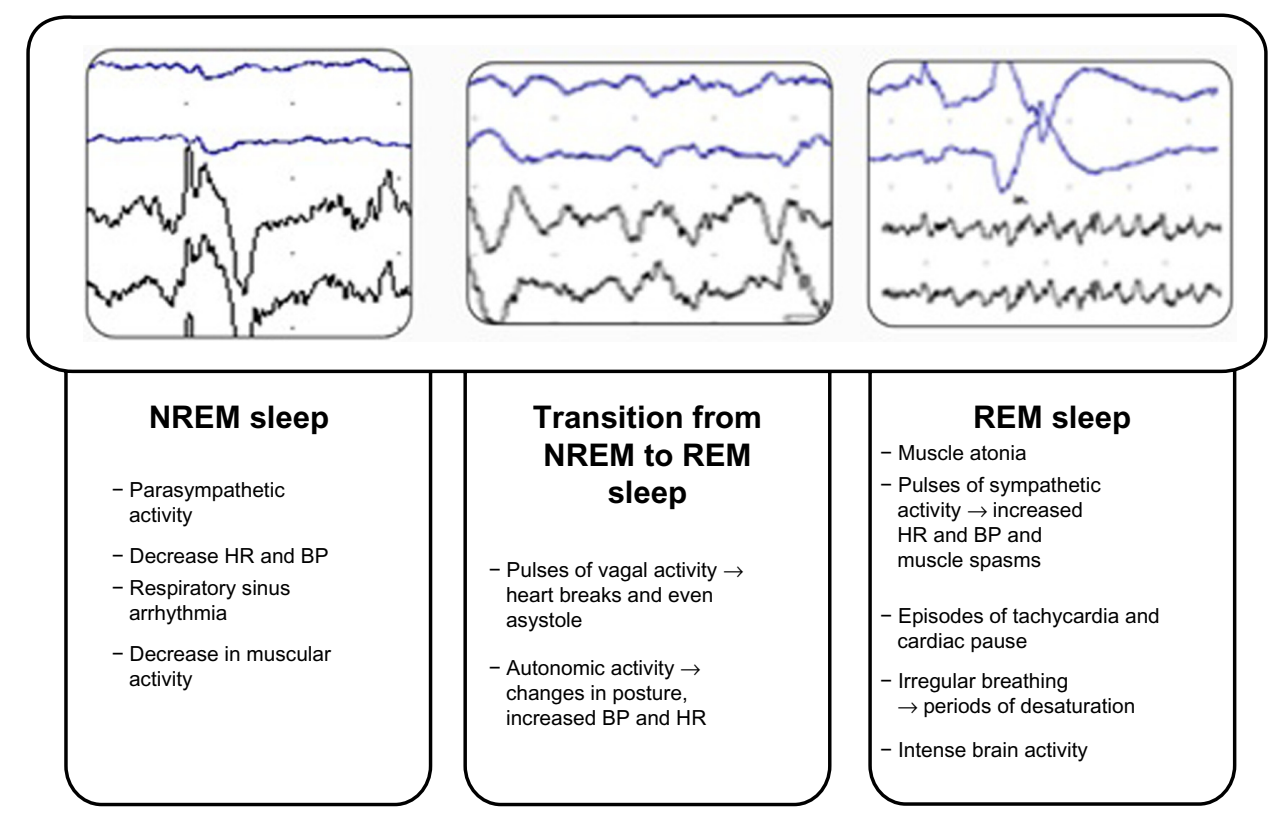

Figure I Physiological changes that occur during sleep phases.

Abbreviations: NREM, nonrapid eye movement; REM, rapid eye movement; HR, heart rate; BP, blood pressure. 


\section{Mechanisms of cardiac disturbance}

OSA is characterized by recurrent episodes of partial (hypopnea) or complete (apnea) interruption of breathing during sleep due to airway collapse in the pharyngeal region. This collapse usually occurs on the posterior part of the tongue, uvula, and soft palate, or some combination of these structures.?

\section{Hypoxemia and reoxygenation}

Patients with OSA typically have repeated periods of desaturation and reoxygenation of oxyhemoglobin (Figure 2). This may partly explain the increase in blood pressure due to chemoreflex-mediated increases in sympathetic activity that induces peripheral vasoconstriction. ${ }^{7,32,33}$ Another pathway for maintaining high blood pressure is related to activation of the renin-angiotensin-aldosterone system, which is also triggered by intermittent hypoxemia. ${ }^{34}$ Further, there is increased oxidative stress and reduced production of endothelium-dependent vasodilator substances, ${ }^{35,36}$ such as nitric oxide, ${ }^{37}$ contributing to activation of systemic inflammation.

Hypoxemia has direct and indirect cardiac and vascular effects, including decreased oxygen delivery to the myocardium, and activation of the sympathetic nervous system, promotion of endothelial cell dysfunction, and pulmonary arteriolar vasoconstriction. ${ }^{38}$ Hypoxemia with reoxygenation may be analogous to ischemia with reperfusion, and may cause additional damage through further production of free radical species. ${ }^{38}$

Decreased myocardial oxygen delivery may result in an imbalance between oxygen consumption and demand, causing myocardial hypoxia, mainly in patients with coronary artery disease. ${ }^{38}$ Endothelial cells in the coronary vessels also play a central role in vasoregulation, coagulation, and inflammation. ${ }^{39}$ Blood flow and coagulation are modulated by production and release of vasoactive substances, a balance of which is important in modulating coronary artery blood flow and coagulation. ${ }^{38}$

The pathophysiological consequences of hypoxemia and reoxygenation could lead to vascular inflammation and remodeling, similar to atherosclerosis. ${ }^{38-40}$ OSA increases sympathetic activity via complex mechanisms. Hypoxemia stimulates peripheral arterial chemoreceptors in the carotid bodies, triggering increased reflex sympathetic activity. ${ }^{38,41,42}$ Hypercapnia acts primarily on central chemoreceptors located in the region of the brainstem, also increasing sympathetic activity. ${ }^{38}$

\section{Arousals}

Sleep architecture is altered in patients with OSA, who show a prevalence of light sleep stages, resulting in arousals that are associated with an increase in sympathetic activity, a decrease in parasympathetic activity, and elevation of blood pressure and heart rate. , $38,43,44^{-1}$

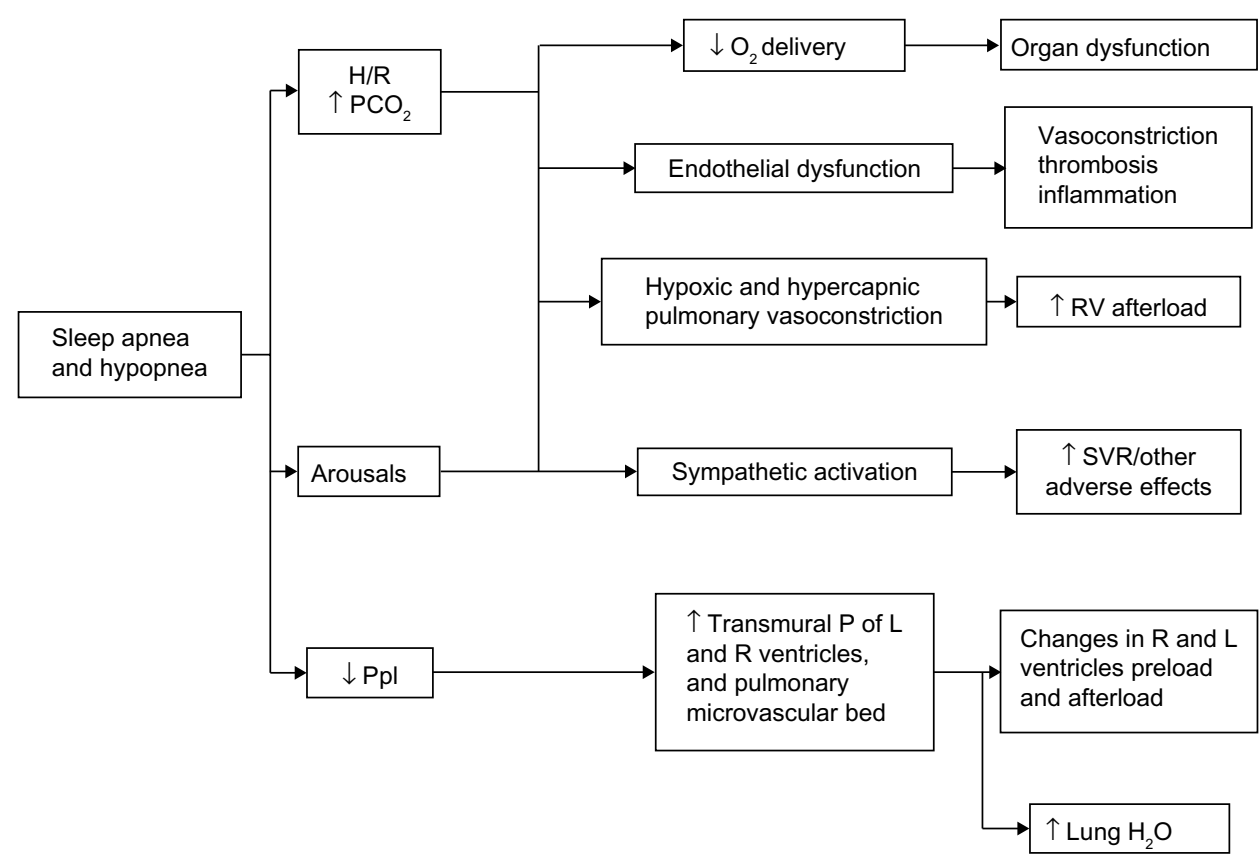

Figure 2 Pathophysiological consequences of obstructive sleep apnea

Note: Reprinted from Principles and Practice of Sleep Medicine. 5th ed. Kryger MH, Roth T, Dement WC, editors. Somers VK, Javaheri S. Cardiovascular effects of sleep-related breathing disorders, 1370-1380. (c) 20II, with permission from Elsevier. ${ }^{38}$

Abbreviations: H/R, hypoxia-reoxygenation; L, left; R, right; RV, right ventricular; SVR, systemic vascular resistance; $\downarrow$, decrease, $\uparrow$, increase; Ppl, pleural pressure; $O_{2}$, oxygen; $\mathrm{H}_{2} \mathrm{O}$, water; $\mathrm{P}$, pressure; $\mathrm{PCO}_{2}$, partial pressure of carbon dioxide. 


\section{Negative intrathoracic pressure}

During the obstructive episode, generation of a significant gradient of negative pressure in the thoracic cavity is required in order to open the upper airway. ${ }^{7}$ This increases the transmural pressure of the intrathoracic vascular structures, including the aorta, pulmonary vascular bed, and ventricles, ${ }^{38}$ possibly resulting in cardiovascular hemodynamic and structural changes. ${ }^{7,45}$

\section{Hypertension}

Hypertension is currently the most important risk factor for cardiovascular disease, which is a leading cause of death worldwide. ${ }^{46,47}$ In spite of efforts to reach blood pressure targets, the results have been disappointing in most countries. Canada shows a control rate of $65 \%,{ }^{48}$ while in the $\mathrm{USA}^{49}$ it is only $50 \%$, and less than one third in other parts of the world. ${ }^{47,50}$ Since the prevalence of difficult to control hypertension has increased in recent decades, ${ }^{51}$ patients with so-called resistant hypertension have become a remarkable clinical entity.

Resistant hypertension is defined by patients being treated, for at least three months, with three classes of antihypertensive drugs at optimal doses, ideally one being a diuretic, without blood pressure control, or requiring four or more classes to achieve the therapeutic goal. ${ }^{51}$

Although the exact prevalence is still discussed, it is estimated that $20 \%-30 \%$ of patients in clinical trials have resistant hypertension. ${ }^{51}$ More recently, however, studies analyzing the prevalence of resistant hypertension showed lower percentages between $12 \%$ and $16 \%{ }^{52,53}$ Aging and obesity are important risk factors leading to decreased blood pressure control, and the incidence of resistant hypertension tends to increase as the population becomes older and more obese. ${ }^{54}$

Among hypertensive patients, at least $5 \%-10 \%$ have an identifiable etiology for their hypertension, characterizing a secondary cause of the increased blood pressure. ${ }^{46}$ Excluding poor adherence with proposed therapy and the effect of white coat hypertension, secondary causes for hypertension must be screened for, such as OSA, aldosteronism, kidney disease, pheochromocytoma, and renovascular disease, especially in patients with resistant hypertension. Given that OSA has been recognized as the major secondary cause of resistant hypertension, ${ }^{51}$ clinical investigation for apnea is mandatory in this population.

\section{Blood pressure pattern and OSA}

Classically, OSA has been associated with a "nondipping blood pressure profile", usually defined as a nocturnal fall in blood pressure of less than $10 \%,{ }^{55}$ regardless of the presence of hypertension in the daytime. ${ }^{7,56,57}$ However, more recent data disagree with this paradigm. ${ }^{23}$ Although controversial, there are studies suggesting that the time between ambulatory blood pressure monitoring measurements should be less in patients with OSA. ${ }^{58}$ On the other hand, age-related differences have been described, suggesting that severe apnea may cause nondipping blood pressure only in young OSA patients, whereas, in the elderly, impaired sleep quality was more prevalent. ${ }^{59}$

In general, the nondipping blood pressure pattern during sleep results from increased sympathetic activity during this period, due to four main stimuli, ie, intermittent hypoxemia, hypercapnia, lack of proper inflation of the lungs, and awakenings at the end of episodes of apnea. ${ }^{7}$ The cumulative effect of excessive sympathetic activation together with other vasoactive factors released in response to hypoxia can result in sustained daytime hypertension in these patients.

\section{Aldosterone and fluid retention}

The high prevalence of OSA in people with resistant hypertension suggests that particular pathophysiological mechanisms may be involved. In patients with resistant hypertension, high sodium intake leads to increased fluid retention, ${ }^{60}$ which could make edema in the region of the upper airways worse. Consistent with this hypothesis, it has been observed that individuals with resistant hypertension have more intense volume redistribution during sleep when compared with individuals who do not have resistant hypertension, and due to the horizontal position, the excess amount withheld during wakefulness is directed from the lower limbs to the cervical region. ${ }^{61}$

Parallel to resistant hypertension, it is questionable whether OSA itself could lead to increased volume retention. ${ }^{62,63}$ Activation of the renin-angiotensin-aldosterone system and sympathetic nervous system alone explains this phenomenon, in addition to the hypertension resulting from activation of these systems. ${ }^{7}$

Other studies indicate that measures reducing fluid retention may contribute to improved $\mathrm{AHI}$ in patients with OSA, including use of compression stockings in those with chronic venous insufficiency, ${ }^{64}$ regular physical activity, ${ }^{65,66}$ and spironolactone. ${ }^{60}$

Among subjects with resistant hypertension, a significant prevalence of aldosteronism can be observed, that reaches $28 \%{ }^{20,67,68}$ In individuals with resistant hypertension, aldosterone excess promotes greater fluid retention, worsening OSA severity. On the other hand, OSA may further increase sympathetic nervous and renin-angiotensin- 
aldosterone systems activity, exacerbating volume retention, and deteriorating blood pressure. In order to assess this pathway better, patients with resistant hypertension and OSA were investigated by Gaddam et al before and 8 weeks after having spironolactone 25-50 $\mathrm{mg}$ /day added to their ongoing antihypertensive therapy. ${ }^{60}$ After treatment, the AHI was significantly reduced from $39.8 \pm 19.5$ events per hour to $22.0 \pm 6.8$ events per hour $(P<0.05) .{ }^{60}$ Although it is not possible to directly infer causality from these studies, the results are consistent with the hypothesis that an excess of aldosterone may contribute to worsening severity of OSA, perhaps secondary to increased airway edema. ${ }^{61}$

Elevated levels of aldosterone and angiotensin II have been observed in OSA, and, interestingly, these levels have been shown to decrease after treatment with CPAP. ${ }^{69}$

Currently, the role of OSA as a risk factor for hypertension is well established. ${ }^{13,70-72}$ Individuals diagnosed with hypertension are about twice as likely to have OSA than individuals without hypertension. ${ }^{71}$ The odds ratios for the presence of hypertension at 4-year follow-up are 1.4 (95\% confidence interval 1.1-1.8) for patients with an AHI of 0.1-4.9 events per hour, 2.0 (95\% confidence interval 1.3-3.2) with an AHI of 5.0-14.9 events per hour, and 2.9 (95\% confidence interval 1.5-5.6) with an AHI $\geq 15.0$ events per hour ${ }^{13}$ at baseline as compared with those without respiratory events. In conclusion, hypertension presence is correlated to OSA severity.

\section{Renal denervation}

Renal sympathetic denervation has been evaluated in several studies as a therapeutic option for patients with resistant hypertension, because it reduces systemic sympathetic activity. At 6-month follow-up, the Renal Denervation in Patients With Uncontrolled Hypertension (Symplicity HTN-2) trial (ClinicalTrials.gov identifier NCT00888433) showed that patients undergoing denervation had a greater reduction in blood pressure from baseline compared with a control group that was not subjected to the procedure. ${ }^{73}$ Interestingly, a review of ten patients with resistant hypertension undergoing renal sympathetic denervation showed a trend towards reduction in AHI from baseline (mean 16.3 events versus 4.5 events per hour, $P=0.059) .{ }^{74}$ This finding was attributed to, among other factors, lower renal and systemic sympathetic activation that could have been achieved with renal denervation, further leading to lower activation of the renin-angiotensin-aldosterone system and therefore lower volume retention. It is important to note that data from the recent published SYMPLICITY HTN-3 trial, a single-blind, randomized controlled trial, failed to show blood pressure decrease after renal denervation in subjects with resistant hypertension. ${ }^{75}$

\section{Arrhythmias}

Cardiac arrhythmias are common in patients with OSA, and the prognosis is highly dependent on the presence of underlying heart disease. ${ }^{76}$ Cardiac arrhythmias such as atrial fibrillation ${ }^{77,78}$ and ventricular arrhythmia ${ }^{78,79}$ are common in patients with OSA, and are associated with increased risk of sudden death during sleep. ${ }^{80}$ Over $50 \%$ of patients with OSA have nocturnal arrhythmias and the frequency of arrhythmias increases with the AHI and severity of hypoxemia. ${ }^{81}$ The risk of an episode of atrial fibrillation or nonsustained ventricular tachycardia 90 minutes after an episode of apnea/hypopnea is 18 times higher than during periods of normal breathing. ${ }^{81}$

In 2006, Mehra et $\mathrm{al}^{78}$ compared 228 patients with and 338 patients without respiratory sleep disorders. Patients with severe disturbances showed a 2-4-fold increased risk of nocturnal complex arrhythmias such as atrial fibrillation and nonsustained ventricular tachycardia, even after adjustment for age, sex, body mass index, and presence of coronary artery disease. In 2009, Monahan et al ${ }^{81}$ studied 57 patients with sleep-disordered breathing in order to establish a direct temporal relationship between the presence of the disorder and the formation of arrhythmias. In these patients, there was an increased relative risk of paroxysmal atrial fibrillation and nonsustained ventricular tachycardia during sleep shortly after an episode of apnea/ hypopnea.

\section{Atherosclerosis}

Atherosclerosis is the pathophysiological basis for most cardiovascular diseases, and its relationship with OSA has been demonstrated in several studies. ${ }^{82}$ Among the main mechanisms involved are intermittent hypoxia associated with increased oxidative stress, endothelial dysfunction, and inflammatory activity. ${ }^{7,82-84}$ Consequently, dyslipidemia, hypertension, and other cardiovascular risk factors may occur, ${ }^{7,83,85}$ the final outcome of which is often death by acute coronary syndrome or stroke. ${ }^{86}$

A prospective study of 4,422 patients with a mean follow-up of 8.7 years, after adjustment for multiple risk factors and excluding patients with coronary artery disease and heart failure, showed that OSA was a significant risk factor for myocardial infarction, need for coronary revascularization, and death from coronary artery disease only in men younger 
than 70 years. Meanwhile, in individuals $40-70$ years, those with an AHI of $>30$ events per hour were $68 \%$ more likely to develop coronary heart disease than those with an AHI of $<5$ events per hour. ${ }^{87}$

Acute coronary syndrome may be associated with OSA because of increased sympathetic tone, leading to increased blood pressure and chronotropism, generating an increase in cardiac output and hence myocardial work. ${ }^{88}$ However, in these cases, the relevant pathophysiological substrate is endothelial dysfunction. Flow-mediated dilation of the brachial artery can be used to evaluate endothelial dysfunction in patients after an acute coronary event. A study comparing patients with OSA and an AHI of $>15$ events per hour and patients without OSA used this technique and obtained significant impairment of endothelial function in the OSA group. An association was also obtained between the drop in oxygen saturation and measurement of endothelial function $(P<0.001)$, indicating a probable relationship between endothelial dysfunction and hypoxemia, with the possible consequence of myocardial infarction. ${ }^{89}$

\section{Heart failure}

The prevalence of OSA in patients with heart failure varies from $10 \%$ to $35 \%,{ }^{90-92}$ and more than half of patients with OSA have diastolic dysfunction that tends to improve with CPAP. ${ }^{93}$ The presence of OSA increases nocturnal sympathetic activation with consequent elevation of blood pressure. This increase in blood pressure is the mechanism directly responsible for left ventricular systolic dysfunction, besides being the most common risk factor for left ventricular hypertrophy. ${ }^{94}$ The increased levels of cytokines, catecholamines, and endothelial growth factors involved in the pathophysiology of OSA also contribute to the onset of left ventricular hypertrophy, independent of the presence of hypertension. ${ }^{95}$ Further, nocturnal hypoxia is an independent risk factor for impaired ventricular relaxation during diastole, which causes further stress on the ventricular wall, favoring the expansion of this chamber and a worse longterm prognosis. ${ }^{96}$

When negative inspiratory intrathoracic pressure is exerted against the occluded pharynx, left ventricular transmural pressure increases and so does the preload. This mechanism also increases venous return, thereby increasing preload in the right ventricle. Meanwhile, hypoxia causes vasoconstriction of the pulmonary vessels, increasing afterload in the right ventricle. The combination of increased afterload and lower preload in the left ventricle leads to a progressive reduction in stroke volume and cardiac output. ${ }^{97}$
Left ventricular hypertrophy may be associated with OSA independently of blood pressure, ${ }^{98,99}$ mainly because of post-load elevation during apnea events and sympathetic activation. ${ }^{100}$ The prevalence of left ventricular hypertrophy increases as the severity of OSA increases..$^{57,100}$

OSA also contributes to the progression of heart failure via other mechanisms, such as increased sympathetic stimulation of the heart, kidneys, and blood vessels during sleep and wakefulness, hypercapnia, daytime blood pressure, and loss of vagal regulation of heart rate. ${ }^{101}$ These mechanisms are recurrent during sleep and cause significant pressure overload in the left ventricle, as well as necrosis and apoptosis of myocytes, and are responsible for the increased risk of acute myocardial infarction, systolic dysfunction, arrhythmias, and cardiac remodeling. ${ }^{101}$

\section{Impact of OSA treatment on blood pressure}

Since a $10 \%$ decrease in body weight can reduce the AHI and improve oxygenation, sleep architecture, blood pressure, and self-reported alertness, control of obesity should be aimed for. ${ }^{102,103}$ The benefit of effective treatment of OSA with CPAP for blood pressure is proportional to its length of use and is demonstrated by a reduction in sympathetic activity. ${ }^{104}$ Meta-analyses suggest that regular CPAP therapy for at least 5 hours per night in patients with OSA results in benefit, reducing both systolic and diastolic blood pressure, with a decrease of $1.69 \mathrm{mmHg}$ in mean blood pressure levels measured during 24-hour ambulatory monitoring. ${ }^{105}$ The best predictors of response are the severity of OSA, higher blood pressure levels, and greater adherence to CPAP. ${ }^{106,107}$

However, not all studies confirm these benefits, and their results should be interpreted with caution, considering the different study designs, inclusion of heterogeneous populations, variations in the definition of hypertension and OSA, classification of OSA severity, duration of use of CPAP, and the methods used to monitor blood pressure. ${ }^{108}$ On the other hand, there is no current evidence that any specific antihypertensive drug has a direct effect on attenuating the severity of OSA, but there is some evidence that some of these agents can interfere with sleep architecture.

\section{Conclusion}

The relationship between sleep-disordered breathing, cardiovascular disease, and its risk factors have been described, but prospective studies analyzing their relationship and the longterm prognosis are still needed. Nevertheless, alterations in 
cardiac function along with hypertension are well established complications of OSA, demanding particular attention to OSA diagnosis in hypertensive patients. Despite the reported benefits of CPAP in the treatment of OSA, the CPAP impact on long-term follow-up and on cardiovascular disease should be better assessed.

\section{Disclosure}

The authors report no conflicts of interest in this work.

\section{References}

1. Lewington S, Clarke R, Qizilbash N, Peto R, Collins R. Age-specific relevance of usual blood pressure to vascular mortality: a meta-analysis of individual data for one million adults in 61 prospective studies. Lancet. 2002;360(9349):1903-1913.

2. Dzau VJ, Antman EM, Black HR, et al. The cardiovascular disease continuum validated: clinical evidence of improved patient outcomes: part I: Pathophysiology and clinical trial evidence (risk factors through stable coronary artery disease). Circulation. 2006;114(25): 2850-2870.

3. Kapur V, Strohl KP, Redline S, Iber C, O'Connor G, Nieto J. Underdiagnosis of sleep apnea syndrome in US communities. Sleep Breath. 2002;6(2):49-54.

4. Young T, Evans L, Finn L, Palta M. Estimation of the clinically diagnosed proportion of sleep apnea syndrome in middle-aged men and women. Sleep. 1997;20(9):705-706.

5. Tufik S, Santos-Silva R, Taddei JA, Bittencourt LR. Obstructive sleep apnea syndrome in the Sao Paulo Epidemiologic Sleep Study. Sleep Med. 2010;11(5):441-446.

6. Wolk R, Shamsuzzaman AS, Somers VK. Obesity, sleep apnea, and hypertension. Hypertension. 2003;42(6):1067-1074.

7. Somers VK, White DP, Amin R, et al. Sleep apnea and cardiovascular disease: an American Heart Association/American College of Cardiology Foundation Scientific Statement from the American Heart Association Council for High Blood Pressure Research Professional Education Committee, Council on Clinical Cardiology, Stroke Council, and Council on Cardiovascular Nursing. In collaboration with the National Heart, Lung, and Blood Institute National Center on Sleep Disorders Research (National Institutes of Health). Circulation 2008;118(10):1080-1111.

8. Drager LF, Genta PR, Pedrosa RP, et al. Characteristics and predictors of obstructive sleep apnea in patients with systemic hypertension. Am J Cardiol. 2010;105(8):1135-1139.

9. Cintra FD, Tufik S, Paola A, et al. Cardiovascular profile in patients with obstructive sleep apnea. Arq Bras Cardiol. 2011;96(4):293-299.

10. Hla KM, Young TB, Bidwell T, Palta M, Skatrud JB, Dempsey J. Sleep apnea and hypertension. A population-based study. Ann Intern Med. 1994;120(5):382-388.

11. Young T, Peppard P, Palta M, et al. Population-based study of sleepdisordered breathing as a risk factor for hypertension. Arch Intern Med. 1997;157(15):1746-1752.

12. Nieto FJ, Young TB, Lind BK, et al. Association of sleep-disordered breathing, sleep apnea, and hypertension in a large community-based study. Sleep Heart Health Study. JAMA. 2000;283(14):1829-1836.

13. Peppard PE, Young T, Palta M, Skatrud J. Prospective study of the association between sleep-disordered breathing and hypertension. N Engl J Med. 2000;342(19):1378-1384.

14. Punjabi NM, Caffo BS, Goodwin JL, et al. Sleep-disordered breathing and mortality: a prospective cohort study. PLoS Med. 2009;6(8):e1000132.

15. Young T, Peppard PE, Gottlieb DJ. Epidemiology of obstructive sleep apnea: a population health perspective. Am J Respir Crit Care Med. 2002;165(9):1217-1239.
16. Myers KA, Mrkobrada M, Simel DL. Does this patient have obstructive sleep apnea?: The Rational Clinical Examination systematic review. JAMA . 2013;310(7):731-741.

17. Fletcher EC, DeBehnke RD, Lovoi MS, Gorin AB. Undiagnosed sleep apnea in patients with essential hypertension. Ann Intern Med. 1985;103(2):190-195.

18. Lavie P, Ben-Yosef R, Rubin AE. Prevalence of sleep apnea syndrome among patients with essential hypertension. Am Heart J. 1984;108(2): 373-376.

19. Worsnop CJ, Naughton MT, Barter CE, Morgan TO, Anderson AI, Pierce RJ. The prevalence of obstructive sleep apnea in hypertensives. Am J Respir Crit Care Med. 1998;157(1):111-115.

20. Gonzaga CC, Gaddam KK, Ahmed MI, et al. Severity of obstructive sleep apnea is related to aldosterone status in subjects with resistant hypertension. J Clin Sleep Med. 2010;6(4):363-368.

21. Logan AG, Perlikowski SM, Mente A, et al. High prevalence of unrecognized sleep apnoea in drug-resistant hypertension. J Hypertens. 2001;19(12):2271-2277.

22. Lloberes P, Lozano L, Sampol G, et al. Obstructive sleep apnoea and 24-h blood pressure in patients with resistant hypertension. J Sleep Res. 2010;19(4):597-602.

23. Pedrosa RP, Drager LF, Gonzaga CC, et al. Obstructive sleep apnea: the most common secondary cause of hypertension associated with resistant hypertension. Hypertension. 2011;58(5):811-817.

24. Johns MW. A new method for measuring daytime sleepiness: the Epworth sleepiness scale. Sleep. 1991;14(6):540-545.

25. Netzer NC, Stoohs RA, Netzer CM, Clark K, Strohl KP. Using the Berlin Questionnaire to identify patients at risk for the sleep apnea syndrome. Ann Intern Med. 1999;131(7):485-491.

26. Ryan CF, Love LL, Peat D, Fleetham JA, Lowe AA. Mandibular advancement oral appliance therapy for obstructive sleep apnoea: effect on awake calibre of the velopharynx. Thorax. 1999;54(11): 972-977.

27. Hoffstein V. Review of oral appliances for treatment of sleep-disordered breathing. Sleep Breath. 2007;11(1):1-22.

28. Sutherland K, Vanderveken OM, Tsuda H, et al. Oral appliance treatment for obstructive sleep apnea: an update. J Clin Sleep Med. 2014;10(2):215-227.

29. Epstein LJ, Kristo D, Strollo PJ Jr, et al. Clinical guideline for the evaluation, management and long-term care of obstructive sleep apnea in adults. J Clin Sleep Med. 2009;5(3):263-276.

30. Elshaug AG, Moss JR, Southcott AM, Hiller JE. Redefining success in airway surgery for obstructive sleep apnea: a meta analysis and synthesis of the evidence. Sleep. 2007;30(4):461-467.

31. Verrier RLM, MA. Sleep-related cardiac risk. In: Kryger MH, Roth T, Dement WC, editors. Principles and Practice of Sleep Medicine. 5th ed. St Louis, MO, USA: Elsevier Saunders; 2011.

32. Narkiewicz K, van de Borne PJ, Pesek CA, Dyken ME, Montano N, Somers VK. Selective potentiation of peripheral chemoreflex sensitivity in obstructive sleep apnea. Circulation. 1999;99(9):1183-1189.

33. Narkiewicz K, van de Borne PJ, Cooley RL, Dyken ME, Somers VK. Sympathetic activity in obese subjects with and without obstructive sleep apnea. Circulation. 1998;98(8):772-776.

34. Fletcher EC, Bao G, Li R. Renin activity and blood pressure in response to chronic episodic hypoxia. Hypertension. 1999;34(2):309-314.

35. Kato M, Roberts-Thomson P, Phillips BG, et al. Impairment of endothelium-dependent vasodilation of resistance vessels in patients with obstructive sleep apnea. Circulation. 2000;102(21): 2607-2610.

36. Gjorup PH, Sadauskiene L, Wessels J, Nyvad O, Strunge B, Pedersen EB. Abnormally increased endothelin-1 in plasma during the night in obstructive sleep apnea: relation to blood pressure and severity of disease. Am J Hypertens. 2007;20(1):44-52.

37. Ip MS, Lam B, Chan LY, et al. Circulating nitric oxide is suppressed in obstructive sleep apnea and is reversed by nasal continuous positive airway pressure. Am J Respir Crit Care Med. 2000;162(6): 2166-2171. 
38. Somers VK, Javaheri S. Cardiovascular effects of sleep-related breathing disorders. In: Kryger MH, Roth T, Dement WC, editors. Principles and Practice of Sleep Medicine. 5th ed. St Louis, MO, USA: Elsevier Saunders; 2011:1370-1380.

39. Mombouli JV, Vanhoutte PM. Endothelial dysfunction: from physiology to therapy. J Mol Cell Cardiol. 1999;31(1):61-74.

40. Biegelsen ES, Loscalzo J. Endothelial function and atherosclerosis. Coron Artery Dis. 1999;10(4):241-256.

41. Somers VK, Mark AL, Zavala DC, Abboud FM. Contrasting effects of hypoxia and hypercapnia on ventilation and sympathetic activity in humans. J Appl Physiol (1985). 1989;67(5):2101-2106.

42. Somers VK, Mark AL, Zavala DC, Abboud FM. Influence of ventilation and hypocapnia on sympathetic nerve responses to hypoxia in normal humans. J Appl Physiol (1985). 1989;67(5):2095-2100.

43. Somers VK, Dyken ME, Mark AL, Abboud FM. Sympathetic-nerve activity during sleep in normal subjects. N Engl J Med. 1993;328(5): 303-307.

44. Horner RL, Brooks D, Kozar LF, Tse S, Phillipson EA. Immediate effects of arousal from sleep on cardiac autonomic outflow in the absence of breathing in dogs. J Appl Physiol (1985). 1995;79(1):151-162.

45. Weiss JW, Remsburg S, Garpestad E, Ringler J, Sparrow D, Parker JA. Hemodynamic consequences of obstructive sleep apnea. Sleep. 1996;19(5):388-397.

46. Sociedade Brasileira de Cardiologia; Sociedade Brasileira de Hipertensão; Sociedade Brasileira de Nefrologia. [VI Brazilian Guidelines on Hypertension]. Arq Bras Cardiol. 2010;95(Suppl 1):1-51. Portuguese.

47. Kearney PM, Whelton M, Reynolds K, Whelton PK, He J. Worldwide prevalence of hypertension: a systematic review. J Hypertens. 2004;22(1):11-19.

48. McAlister FA, Wilkins $\mathrm{K}$, Joffres $\mathrm{M}$, et al. Changes in the rates of awareness, treatment and control of hypertension in Canada over the past two decades. CMAJ. 2011;183(9):1007-1013.

49. Egan BM, Zhao Y, Axon RN. US trends in prevalence, awareness, treatment, and control of hypertension, 1988-2008. JAMA. 2010;303(20):2043-2050.

50. Cipullo JP, Martin JF, Ciorlia LA, et al. [Hypertension prevalence and risk factors in a Brazilian urban population]. Arq Bras Cardiol. 2010;94(4):519-526. Portuguese.

51. Calhoun DA, Jones D, Textor S, et al. Resistant hypertension: diagnosis, evaluation, and treatment: a scientific statement from the American Heart Association Professional Education Committee of the Council for High Blood Pressure Research. Circulation. 2008;117(25):e510-e526.

52. de la Sierra A, Segura J, Banegas JR, et al. Clinical features of 8295 patients with resistant hypertension classified on the basis of ambulatory blood pressure monitoring. Hypertension. 2011;57(5): 898-902.

53. Daugherty SL, Powers JD, Magid DJ, et al. Incidence and prognosis of resistant hypertension in hypertensive patients. Circulation. 2012; 125(13):1635-1642.

54. Egan BM, Zhao Y, Axon RN, Brzezinski WA, Ferdinand KC. Uncontrolled and apparent treatment resistant hypertension in the United States, 1988 to 2008. Circulation. 2011;124(9):1046-1058.

55. O'Brien E, Parati G, Stergiou G, et al. European Society of Hypertension position paper on ambulatory blood pressure monitoring. J Hypertens. 2013;31(9):1731-1768.

56. Davies CW, Crosby JH, Mullins RL, Barbour C, Davies RJ, Stradling JR. Case-control study of 24 hour ambulatory blood pressure in patients with obstructive sleep apnoea and normal matched control subjects. Thorax. 2000;55(9):736-740.

57. Baguet JP, Barone-Rochette G, Pepin JL. Hypertension and obstructive sleep apnoea syndrome: current perspectives. J Hum Hypertens. 2009;23(7):431-443.

58. Marrone O, Romano S, Insalaco G, Bonsignore MR, Salvaggio A, Bonsignore G. Influence of sampling interval on the evaluation of nocturnal blood pressure in subjects with and without obstructive sleep apnoea. Eur Respir J. 2000;16(4):653-658.
59. Sasaki N, Ozono R, Yamauchi R, et al. Age-related differences in the mechanism of nondipping among patients with obstructive sleep apnea syndrome. Clin Exp Hypertens. 2012;34(4):270-277.

60. Gaddam K, Pimenta E, Thomas SJ, et al. Spironolactone reduces severity of obstructive sleep apnoea in patients with resistant hypertension: a preliminary report. J Hum Hypertens. 2010;24(8):532-537.

61. Friedman O, Bradley TD, Chan CT, Parkes R, Logan AG. Relationship between overnight rostral fluid shift and obstructive sleep apnea in drug-resistant hypertension. Hypertension. 2010;56(6): 1077-1082.

62. Mirrakhimov AE. Supine fluid redistribution: should we consider this as an important risk factor for obstructive sleep apnea? Sleep Breath. 2013;17(2):511-523

63. Fischer MK, Martinez D, Cassol CM, Rahmeier L, Vieira LR. Immediate and overnight recumbence-dependent changes of neck circumference: relationship with OSA severity in obese and nonobese subjects. Sleep Med. 2012;13(6):650-655.

64. Redolfi S, Arnulf I, Pottier M, et al. Attenuation of obstructive sleep apnea by compression stockings in subjects with venous insufficiency. Am J Respir Crit Care Med. 2011;184(9):1062-1066.

65. Ueno LM, Drager LF, Rodrigues AC, et al. Effects of exercise training in patients with chronic heart failure and sleep apnea. Sleep. 2009;32(5):637-647.

66. Awad KM, Malhotra A, Barnet JH, Quan SF, Peppard PE. Exercise is associated with a reduced incidence of sleep-disordered breathing. Am J Med. 2012;125(5):485-490.

67. Calhoun DA, Nishizaka MK, Zaman MA, Harding SM. Aldosterone excretion among subjects with resistant hypertension and symptoms of sleep apnea. Chest. 2004;125(1):112-117.

68. Pratt-Ubunama MN, Nishizaka MK, Boedefeld RL, Cofield SS, Harding SM, Calhoun DA. Plasma aldosterone is related to severity of obstructive sleep apnea in subjects with resistant hypertension. Chest. 2007;131(2):453-459.

69. Møller DS, Lind P, Strunge B, Pedersen EB. Abnormal vasoactive hormones and 24-hour blood pressure in obstructive sleep apnea. Am J Hypertens. 2003;16(4):274-280.

70. Guillot M, Sforza E, Achour-Crawford E, et al. Association between severe obstructive sleep apnea and incident arterial hypertension in the older people population. Sleep Med. 2013;14(9):838-842.

71. Asha'ari ZA, Hasmoni MH, Ab Rahman J, Yusof RA, Ahmad RA. The association between sleep apnea and young adults with hypertension. Laryngoscope. 2012;122(10):2337-2342.

72. Marin JM, Agusti A, Villar I, et al. Association between treated and untreated obstructive sleep apnea and risk of hypertension. JAMA. 2012;307(20):2169-2176.

73. Symplicity HTN-2 Investigators, Esler MD, Krum H, et al. Renal sympathetic denervation in patients with treatment-resistant hypertension (The Symplicity HTN-2 Trial): a randomised controlled trial. Lancet. 2010;376(9756):1903-1909.

74. Witkowski A, Prejbisz A, Florczak E, et al. Effects of renal sympathetic denervation on blood pressure, sleep apnea course, and glycemic control in patients with resistant hypertension and sleep apnea. Hypertension. 2011;58(4):559-565.

75. Bhatt DL, Kandzari DE, O'Neill WW, et al. A controlled trial of renal denervation for resistant hypertension. $N$ Engl J Med. 2014;370(15): 1393-1401.

76. Levy P, Ryan S, Oldenburg O, Parati G. Sleep apnoea and the heart. Eur Respir Rev. 2013;22(129):333-352.

77. Gami AS, Hodge DO, Herges RM, et al. Obstructive sleep apnea, obesity, and the risk of incident atrial fibrillation. J Am Coll Cardiol. 2007;49(5):565-571.

78. Mehra R, Benjamin EJ, Shahar E, et al. Association of nocturnal arrhythmias with sleep-disordered breathing: The Sleep Heart Health Study. Am J Respir Crit Care Med. 2006;173(8):910-916.

79. Shepard JW, Garrison MW, Grither DA, Dolan GF. Relationship of ventricular ectopy to oxyhemoglobin desaturation in patients with obstructive sleep apnea. Chest. 1985;88(3):335-340. 
80. Gami AS, Howard DE, Olson EJ, Somers VK. Day-night pattern of sudden death in obstructive sleep apnea. $N$ Engl J Med. 2005;352(12): 1206-1214.

81. Monahan K, Storfer-Isser A, Mehra R, et al. Triggering of nocturnal arrhythmias by sleep-disordered breathing events. J Am Coll Cardiol. 2009;54(19):1797-1804.

82. Drager LF, Polotsky VY, Lorenzi-Filho G. Obstructive sleep apnea: an emerging risk factor for atherosclerosis. Chest. 2011;140(2): 534-542.

83. Lui MM, Sau-Man M. OSA and atherosclerosis. J Thorac Dis. 2012;4(2):164-172.

84. Kylintireas I, Craig S, Nethononda R, et al. Atherosclerosis and arterial stiffness in obstructive sleep apnea - a cardiovascular magnetic resonance study. Atherosclerosis. 2012;222(2):483-489.

85. Seif F, Patel SR, Walia H, et al. Association between obstructive sleep apnea severity and endothelial dysfunction in an increased background of cardiovascular burden. J Sleep Res. 2013;22(4):443-451.

86. Lee CH, Khoo SM, Chan MY, et al. Severe obstructive sleep apnea and outcomes following myocardial infarction. J Clin Sleep Med. 2011;7(6): 616-621.

87. Gottlieb DJ, Yenokyan G, Newman AB, et al. Prospective study of obstructive sleep apnea and incident coronary heart disease and heart failure: the Sleep Heart Health Study. Circulation. 2010;122(4): 352-360

88. Hetzenecker A, Buchner S, Greimel T, et al. Cardiac workload in patients with sleep-disordered breathing early after acute myocardial infarction. Chest. 2013;143(5):1294-1301.

89. Sert Kuniyoshi FH, Singh P, Gami AS, et al. Patients with obstructive sleep apnea exhibit impaired endothelial function after myocardial infarction. Chest. 2011;140(1):62-67.

90. Wang H, Parker JD, Newton GE, et al. Influence of obstructive sleep apnea on mortality in patients with heart failure. J Am Coll Cardiol. 2007;49(15):1625-1631.

91. Javaheri S, Parker TJ, Liming JD, et al. Sleep apnea in 81 ambulatory male patients with stable heart failure. Types and their prevalences, consequences, and presentations. Circulation. 1998;97(21): 2154-2159.

92. Sin DD, Fitzgerald F, Parker JD, Newton G, Floras JS, Bradley TD. Risk factors for central and obstructive sleep apnea in 450 men and women with congestive heart failure. Am J Respir Crit Care Med. 1999;160(4):1101-1106.

93. Arias MA, García-Río F, Alonso-Fernández A, Mediano O, Martínez I, Villamor J. Obstructive sleep apnea syndrome affects left ventricular diastolic function: effects of nasal continuous positive airway pressure in men. Circulation. 2005;112(3):375-383.

94. Levy D, Larson MG, Vasan RS, Kannel WB, Ho KK. The progression from hypertension to congestive heart failure. JAMA. 1996;275(20): 1557-1562.
95. Otto ME, Belohlavek M, Romero-Corral A, et al. Comparison of cardiac structural and functional changes in obese otherwise healthy adults with versus without obstructive sleep apnea. Am J Cardiol. 2007;99(9):1298-1302.

96. Fung JW, Li TS, Choy DK, et al. Severe obstructive sleep apnea is associated with left ventricular diastolic dysfunction. Chest. 2002;121(2):422-429.

97. Kasai T, Bradley TD. Obstructive sleep apnea and heart failure: pathophysiologic and therapeutic implications. J Am Coll Cardiol. 2011;57(2):119-127.

98. Hedner J, Ejnell H, Caidahl K. Left ventricular hypertrophy independent of hypertension in patients with obstructive sleep apnoea. J Hypertens. 1990;8(10):941-946.

99. Kraiczi H, Peker Y, Caidahl K, Samuelsson A, Hedner J. Blood pressure, cardiac structure and severity of obstructive sleep apnea in a sleep clinic population. J Hypertens. 2001;19(11):2071-2078.

100. Noda A, Okada T, Yasuma F, Nakashima N, Yokota M. Cardiac hypertrophy in obstructive sleep apnea syndrome. Chest. 1995;107(6): 1538-1544.

101. Floras JS. Clinical aspects of sympathetic activation and parasympathetic withdrawal in heart failure. J Am Coll Cardiol. 1993; 22(4 Suppl A):72A-84A.

102. Ryan CF. Sleep x 9: an approach to treatment of obstructive sleep apnoea/hypopnoea syndrome including upper airway surgery. Thorax. 2005;60(7):595-604.

103. Kuna ST, Reboussin DM, Borradaile KE, et al. Long-term effect of weight loss on obstructive sleep apnea severity in obese patients with type 2 diabetes. Sleep. 2013;36(5):641a-649a.

104. Waradekar NV, Sinoway LI, Zwillich CW, Leuenberger UA. Influence of treatment on muscle sympathetic nerve activity in sleep apnea. Am J Respir Crit Care Med. 1996;153(4 Pt 1):1333-1338.

105. Haentjens P, Van Meerhaeghe A, Moscariello A, et al. The impact of continuous positive airway pressure on blood pressure in patients with obstructive sleep apnea syndrome: evidence from a meta-analysis of placebo-controlled randomized trials. Arch Intern Med. 2007;167(8): 757-764.

106. Dudenbostel T, Calhoun DA. Resistant hypertension, obstructive sleep apnoea and aldosterone. J Hum Hypertens. 2012;26(5):281-287.

107. Barbe F, Duran-Cantolla J, Sanchez-de-la-Torre M, et al. Effect of continuous positive airway pressure on the incidence of hypertension and cardiovascular events in nonsleepy patients with obstructive sleep apnea: a randomized controlled trial. JAMA. 2012;307(20): 2161-2168.

108. Rao M, Rajda G, Uppuluri S, Beck GR, Liu L, Bisognano JD. The role of continuous positive airway pressure in the treatment of hypertension in patients with obstructive sleep apnea-hypoapnea syndrome: a review of randomized trials. Rev Recent Clin Trials. 2010;5(1):35-42.
Research Reports in Clinical Cardiology

\section{Publish your work in this journal}

Research Reports in Clinical Cardiology is an international, peerreviewed, open access journal publishing original research, reports, editorials, reviews and commentaries on all areas of cardiology in the clinic and laboratory. The manuscript management system is completely online and includes a very quick and fair peer-review system.

\section{Dovepress}

Visit http://www.dovepress.com/testimonials.php to read real quotes from published authors. 